\title{
Complications associated with malposition of atrial septal defect device closure: A case report
}

\author{
Atriyal septal defekt kapatma cihazının malpozisyonuyla ilişkili komplikasyonlar: Olgu sunumu
}

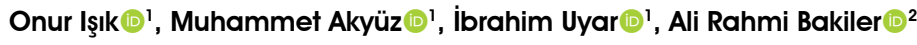

'Department of Pediatric Cardiovascular Surgery, Tepecik Training and Researh Hospital, İmir, Turkey
2Department of Pediatric Cardiology, Tepecik Training and Researh Hospital, İmir, Turkey

\begin{abstract}
A 20-year-old male patient presented with dyspnea on exertion, chest pain, and tightness in chest. The patient's history revealed a percutaneous intervention with device closure of atrial septal defect (ASD) four years ago and dual-chamber pacemaker implantation because of complete AV block 10 days after ASD closure. The patient had occasionally suffered from shortness of breath and was diagnosed with allergic asthma at a center for chest disease and was also followed up by psychiatry for a panic attack diagnosis. The patient had progressively increasing shortness of breath and transthoracic echocardiography was performed in the cardiology clinic. Transthoracic echocardiography revealed malposition of the ASD closure device and its surgical removal was decided.
\end{abstract}

The patient was in good overall health and had normal vital signs. Electrocardiography showed heart rate of $70 / \mathrm{min}$ and normal sinus rhythm, and the pacemaker was offline. The ASD closure device and pacemaker leads/generator were observed in the patient's chest radiography (Figure 1a). Transthoracic echocardiography revealed the closure device was in close proximity to the ventricular septal crest, towards the tricuspid valve septal leaflet and mitral valve anterior leaflet, rather than the ASD rim (Figure 1b). There was no pathology associated with atrioventricular valves. Intravenous contrast computed tomography (CT) revealed that the closure device's disk compressed the left ventricular outflow tract and was not fully inserted in the septum, causing
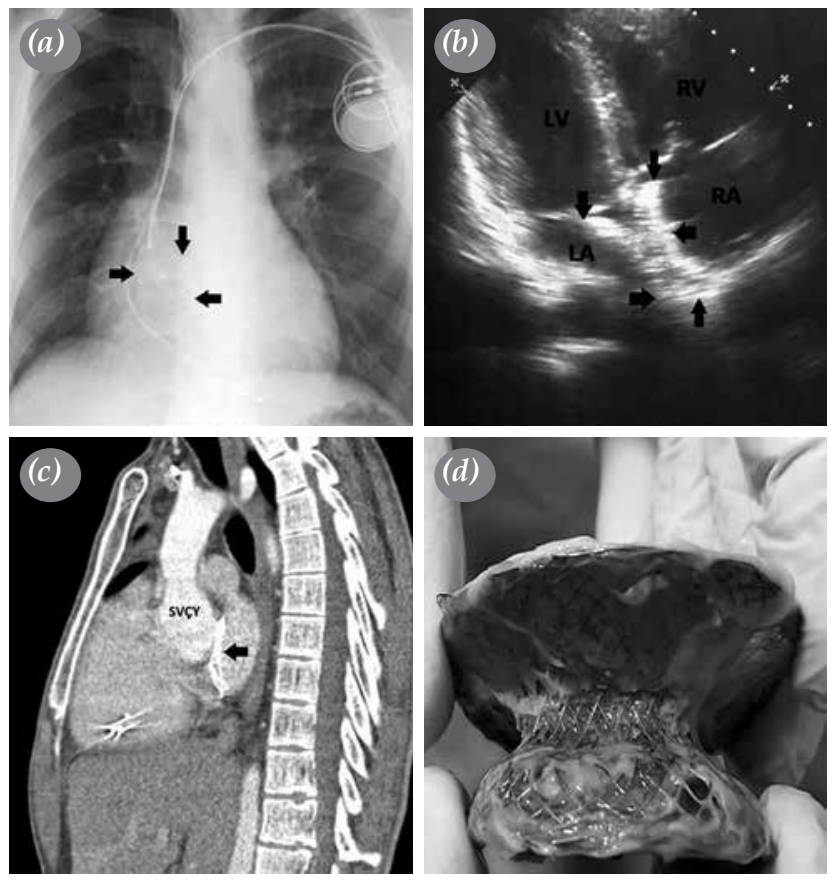

Figure 1. (a) Posteroanterior chest radiograph showing the intravenously inserted pacemaker leads and battery. The borders of the atrial septal defect closure device are observed (arrows). (b) Transthoracic echocardiography. The device takes up too much space in both atriums and the proximity to the atrioventricular valves are observed. (c) Computed tomography with contrast. The device's (arrow) compression to the left ventricular outflow tract and its proximity is shown. (d) The excised atrial septal defect closure device. Note the distance between the disks due to the device's inadequate placement in the septum.

Received: January 30, 2018 Accepted: April 24, 2018

Correspondence: Muhammet Akyüz, MD. Tepecik Eğitim ve Araştırma Hastanesi, Çocuk Kalp Cerrahisi Kliniği, 35180 Yenişehir, Konak, İzmir, Turkey. Tel: +90 232 - 4696969 e-mail: drmak100@gmail.com 
significant distance between the disks (Figure 1c). The patient was operated through a median sternotomy incision. Cardiopulmonary bypass (CPB) was initiated after aortic bicaval cannulation. Arrest was achieved with antegrad cold cardioplegia. Right atriotomy was performed. It was observed that the disks of the device were not fully closed (Figure 1d). The device's disk was ledged above the coronary sinus of the right atrial side and was in close proximity to the septal leaflets. The device protruded from the right atrium lateral wall towards the pericardial wall and was unapproachable from the left atrium, therefore the left atrial cavity was approached with a clear incision from the inferior of the plan. A second dissection route including the right atrial lateral wall neighboring the device was performed freeing the lateral side of the device. A medial resection was performed and the closure device was completely removed (Figure 1d). The tissue located at the aortic proximity of the atrial septal defect was primarily repaired. The defect in the right and left atrium lateral wall (Waterston's groove) was primarily repaired. The atrial septal defect was secondarily repaired with a polyethylene terephthalate (PTFE) patch. The pacemaker leads and battery were removed. After primarily closure of right atriotomy, the CPB was ceased with the heart on sinus rhythm and $5 \mathrm{mcg} / \mathrm{kg} / \mathrm{min}$ dopamine support. The recovery period was uneventful and the patient was discharged on postoperative day 5 .

Percutaneous techniques are essential methods that can be applied with good results in patients with an anatomically adequate septal defect. ${ }^{[1]}$ However they are not considered to be without complications. The type and rate of complications differ in terms of different devices and ASD types. Generally common complications are hematoma (local or retroperitoneal), pseudoaneurysms, hemorrhage, thrombosis, etc. depending on the access route of the vein. ${ }^{[2]}$ However, life-threatening complications such as dissection, temporary or permanent atrioventricular block, coronary compression, cardiac perforation, pericardial tamponade, or device embolization may also occur. ${ }^{[3]}$ Acute surgical intervention may provide good outcomes in the treatment of these complications. ${ }^{[3]}$

It is also important to note that in our case, device-related complications that remained unnoticed lead to progressively worsening symptoms and that late-term excision of the organized device from the cardiac cavity carried significant risk of severe surgical complications. Regular postoperative follow up of patients who have undergone transcatheter atrial septal defect closure may provide a chance for early intervention of complications that may be encountered in the early and midterm, or even lateterm period.

\section{Declaration of conflicting interests}

The authors declared no conflicts of interest with respect to the authorship and/or publication of this article.

\section{Funding}

The authors received no financial support for the research and/or authorship of this article.

\section{REFERENCES}

1. Spence MS, Qureshi SA. Complications of transcatheter closure of atrial septal defects. Heart 2005;91:1512-4.

2. Daniel De Wolf. Complications of transcatheter atrial septal defect closure. Interv Cardiol 2009;1:209-18.

3. Wu HC, Wang CC, Fu YC, Jan SL, Wei HJ, Lin YK, et al. Surgical management for complications during closure of atrial septal defect with amplatzer device. Acta Cardiol Sin 2013;29:557-61. 